\title{
Epidemiologic assessment of benzodiazepine exposure among suicide deaths in Colorado, 2015-2017
}

Tista Ghosh ${ }^{*}$ Di , Kirk Bol, Maria Butler, Barbara Gabella, Andrea Kingcade, Gabriel Kaplan and Lindsey Myers

\begin{abstract}
Background: Suicide rates have been climbing in the U.S., particularly in Rocky Mountain states such as Colorado. Benzodiazepines have been linked with suicidal ideation, but there have been few population level assessments of this link. We conducted a public health assessment to determine the epidemiology and prevalence of recent benzodiazepine exposure, among suicide deaths in Colorado from 2015 to 17.

Methods: This epidemiologic assessment linked Colorado's Prescription Drug Monitoring Program, death certificate data, and Violent Death Reporting System to determine patterns of benzodiazepine exposure among suicide deaths in Colorado between 2015 and 2017. Recent benzodiazepine exposure was defined as receiving a prescription within 30 days of death or having a positive toxicology screen post-mortem.

Results: Among the 3465 suicide deaths in Colorado between 2015 and 2017, 20\% had recent benzodiazepine exposure, and nearly $50 \%$ of those also had recent opioid exposure. Recent benzodiazepine exposure was more common among females than males (34\% versus 16\%). Among suicide deaths, those who died via drug overdose were more likely to have had recent benzodiazepine exposure (48\%), compared to suicides by firearm (17\%), hanging/asphyxiation (13\%) and all other methods (approximately 20\%).

Conclusions: Benzodiazepines have been linked to suicidal ideation, but population level assessments of benzodiazepine exposure among suicide deaths are rare. Our epidemiologic assessment indicates a relatively high prevalence of recent benzodiazepine exposure that warrants further investigation from both clinical and public health perspectives.
\end{abstract}

Keywords: Benzodiazepines, Suicide, Colorado

\section{Background}

Benzodiazepines are a class of psychoactive drugs that are commonly prescribed for conditions such as anxiety, muscle spasms, seizures, insomnia, and alcohol withdrawal. In 2017, more than 1.5 million benzodiazepines prescriptions were dispensed in Colorado, the second most common class of controlled substances, according to the Colorado Prescription Drug Monitoring Program

\footnotetext{
* Correspondence: tista.s.ghosh@gmail.com

Colorado Department of Public Health and Environment, 4300 Cherry Creek Drive South, Denver, CO 80246, USA
}

[1]. Benzodiazepine use is common in Colorado, the U.S., and in other countries, though how use is measured and reported varies in the literature, and use is more common in older ages and women [2-7]. In 2008, $5.2 \%$ of U.S. adults ages $18-80$ years old filled a benzodiazepine prescription [3]. A more recent estimate is that $12.6 \%$ of U.S. adults ages 18 years or older used a benzodiazepine in the last year or $10.4 \%$ used them as prescribed, based on a different data source [8]. High rates of benzodiazepine use, especially long-term use in older adults, might reflect limited access to effective

(c) The Author(s). 2020 Open Access This article is licensed under a Creative Commons Attribution 4.0 International License, which permits use, sharing, adaptation, distribution and reproduction in any medium or format, as long as you give appropriate credit to the original author(s) and the source, provide a link to the Creative Commons licence, and indicate if changes were made. The images or other third party material in this article are included in the article's Creative Commons licence, unless indicated otherwise in a credit line to the material. If material is not included in the article's Creative Commons licence and your intended use is not permitted by statutory regulation or exceeds the permitted use, you will need to obtain permission directly from the copyright holder. To view a copy of this licence, visit http://creativecommons.org/licenses/by/4.0/ The Creative Commons Public Domain Dedication waiver (http://creativecommons.org/publicdomain/zero/1.0/) applies to the data made available in this article, unless otherwise stated in a credit line to the data. 
alternatives and/or patient preference [3, 9]. Benzodiazepines are federally-controlled substances, since long term use has been shown to lead to physical dependence. In addition, recent literature reviews suggest that benzodiazepines may have another negative side effect: suicidal ideation $[10,11]$. However, there has been little study of the role of benzodiazepines in suicide from a public health perspective.

Suicide is a public health crisis in Colorado, resulting in 1271 suicide deaths in 2017. Suicide is consistently a leading cause of death in the state. In 2016, suicide rates increased $25.4 \%$ nationwide since 1999 , and are even higher in the Rocky Mountain states, such as Colorado [12]. In Colorado, the age-adjusted annual rate of suicide was 23.2 deaths per 100,000 persons (2014-2016), a $34.1 \%$ increase from 1999 to 2001 [12]. In comparison, the U.S. rate was 15.4 deaths per 100,000 population (2014-2016) [12]. Numerous risk factors for suicide, ranging from gender to occupation to mental healthcare access to altitude, have been examined [13-15]. However, few analyses have been conducted to assess whether benzodiazepines play a role in suicide at the population level. The Colorado state health department therefore examined the prevalence and patterns of benzodiazepine exposure among suicide deaths, to determine whether further investigation into the role of benzodiazepines is necessary from a population health standpoint. This study was the first of its kind to use two common state public health databases in the U.S.: prescription drug monitoring program and violent death reporting system, which have similar counterparts in other countries.

\section{Methods}

State-employed toxicology staff conducted a literature review to assess biologic plausibility of benzodiazepine use and suicidal ideation, in response to citizen inquiry and concern. This review suggested an increased risk of suicide while on benzodiazepines or when dosing is abruptly stopped or tapered [16-20]. State-employed epidemiologists then examined patterns of benzodiazepine use among suicide deaths by linking Colorado's Prescription Drug Monitoring Program (PDMP), an electronic database that tracks the dispensing of controlled substances, to the Colorado Violent Death Reporting System that contains information from coroners' and medical examiner's records, law enforcement reports, and death certificate data [21, 22].

We defined the study population as suicide deaths occurring in Colorado between 2015 and 2017, identified using Colorado's death certificate registry based on suicide as the underlying cause of death (ICD-10 codes X60-X84 and Y87.0). We subsequently linked these suicide deaths to the Colorado PDMP, comprising approximately 42 milliion records of controlled substances prescriptions dispensed between 2014 and 2018 . This time period represents both the earliest and latest complete year of PDMP data available, which in turn afforded a minimum one-year retrospective of benzodiazepine prescriptions filled prior to death. These suicide deaths were additionally linked to records from the Colorado Violent Death Reporting System from 2015 to 2017, representing the latest complete years of enhanced data concerning toxicology status, including benzodiazepine exposure, at the time of death. We identified three subgroups of suicide deaths: (1) "ever dispensed a benzodiazepine," defined as having received a prescription for a benzodiazepine ever during the timeframe of the look-back at the PDMP data (2014-2017); (2) "recent benzodiazepine exposure," defined as benzodiazepines prescribed within 30 days of death or a positive toxicology for benzodiazepines post-mortem, and (3) "recent benzodiazepine and opioid exposure," defined as those suicide deaths with recent benzodiazepine exposure who were also either prescribed an opioid within 30 days of death, or had positive toxicology post-mortem for opioids. Frequencies of demographic characteristics, mechanism of suicide, and other circumstances were assessed for total suicide deaths and these three subgroups.

\section{Results}

Among the 3465 suicide deaths in Colorado between 2015 and 2017, 60\% were linked to a record in the PDMP, as shown in Table 1. Linking to the PDMP meant that $60 \%$ of suicide deaths filled a prescription for a controlled substance during the 2014-2017 linkage timeframe. Among all 3465 suicide deaths, 31\% had ever filled a benzodiazepine prescription preceding death (within the 2014-2017 linkage timeframe), according to the PDMP (Table 1). Additional information about the 3465 suicide deaths not shown in Table 1: Fourteen percent of the suicide deaths had filled a benzodiazepine prescription within 30 days before death, according to the PDMP. Approximately one-third (34\%) had ever had benzodiazepine exposure. This exposure was defined as either ever filling a benzodiazepine prescription (within the linkage timeframe) as documented in the PDMP, or having positive toxicology post-mortem, per the Violent Death reporting.

We then assessed all 3465 suicide deaths for recent benzodiazepine exposure, which we defined as either receiving a prescription within 30 days of death or having positive toxicology results for benzodiazepines at death. One-fifth $(20 \%)$ of all suicide deaths had recent benzodiazepine exposure (Table 1). Among suicide deaths with recent benzodiazepine exposure, nearly $50 \%$ also either filled an opioid prescription within 30 days of death, or 
Table 1 Colorado suicide deaths between 2015 and 2017, by PDMP linkage status, and benzodiazepine and opioid exposure status

\begin{tabular}{|c|c|c|c|c|c|c|c|c|c|}
\hline & \multirow{2}{*}{$\begin{array}{l}\text { Total suicide deaths } \\
\text { Count }\end{array}$} & \multicolumn{2}{|c|}{$\begin{array}{l}\text { Linked to } \\
\text { PDMP record }\end{array}$} & \multicolumn{2}{|c|}{$\begin{array}{l}\text { Ever dispensed } \\
\text { benzodiazepine }^{a}\end{array}$} & \multicolumn{2}{|c|}{$\begin{array}{l}\text { Recent } \\
\text { benzodiazepine } \\
\text { exposure }\end{array}$} & \multicolumn{2}{|c|}{$\begin{array}{l}\text { Recent } \\
\text { benzodiazepine } \\
\text { and opioid } \\
\text { exposure }^{c}\end{array}$} \\
\hline & & Count & Percent & Count & Percent & Count & Percent & Count & Percent \\
\hline Total & 3465 & 2070 & $59.7 \%$ & 1058 & $30.5 \%$ & 699 & $20.2 \%$ & 331 & $9.6 \%$ \\
\hline \multicolumn{10}{|l|}{ Sex } \\
\hline Female & 792 & 582 & $73.5 \%$ & 373 & $47.1 \%$ & 265 & $33.5 \%$ & 143 & $18.1 \%$ \\
\hline Male & 2673 & 1488 & $55.7 \%$ & 685 & $25.6 \%$ & 434 & $16.2 \%$ & 188 & $7.0 \%$ \\
\hline \multicolumn{10}{|l|}{ Age-Female } \\
\hline $0-14$ yrs & 18 & 7 & $38.9 \%$ & * & $*$ & * & * & * & * \\
\hline $15-19$ yrs & 64 & 29 & $45.3 \%$ & 5 & $7.8 \%$ & 6 & $9.4 \%$ & * & * \\
\hline $20-24$ yrs & 53 & 34 & $64.2 \%$ & 16 & $30.2 \%$ & 11 & $20.8 \%$ & 8 & $15.1 \%$ \\
\hline $25-34$ yrs & 126 & 92 & $73.0 \%$ & 60 & $47.6 \%$ & 42 & $33.3 \%$ & 21 & $16.7 \%$ \\
\hline $35-44$ yrs & 122 & 100 & $82.0 \%$ & 70 & $57.4 \%$ & 43 & $35.2 \%$ & 19 & $15.6 \%$ \\
\hline $45-54$ yrs & 175 & 131 & $74.9 \%$ & 88 & $50.3 \%$ & 64 & $36.6 \%$ & 32 & $18.3 \%$ \\
\hline $55-64$ yrs & 143 & 117 & $81.8 \%$ & 84 & $58.7 \%$ & 54 & $37.8 \%$ & 35 & $24.5 \%$ \\
\hline $65-74$ yrs & 59 & 49 & $83.1 \%$ & 37 & $62.7 \%$ & 31 & $52.5 \%$ & 18 & $30.5 \%$ \\
\hline $75-84$ yrs & 18 & 12 & $66.7 \%$ & 5 & $27.8 \%$ & * & $*$ & * & * \\
\hline $85+y r s$ & 14 & 11 & $78.6 \%$ & 8 & $57.1 \%$ & 7 & $50.0 \%$ & 5 & $35.7 \%$ \\
\hline \multicolumn{10}{|l|}{ Age-Male } \\
\hline $0-14$ yrs & 35 & 8 & $22.9 \%$ & * & * & * & * & * & * \\
\hline $15-19$ yrs & 150 & 46 & $30.7 \%$ & 9 & $6.0 \%$ & 11 & $7.3 \%$ & * & * \\
\hline $20-24$ yrs & 230 & 81 & $35.2 \%$ & 32 & $13.9 \%$ & 19 & $8.3 \%$ & 8 & $3.5 \%$ \\
\hline $25-34$ yrs & 538 & 267 & $49.6 \%$ & 117 & $21.7 \%$ & 76 & $14.1 \%$ & 25 & $4.6 \%$ \\
\hline $35-44$ yrs & 419 & 247 & $58.9 \%$ & 125 & $29.8 \%$ & 79 & $18.9 \%$ & 38 & $9.1 \%$ \\
\hline $45-54$ yrs & 478 & 287 & $60.0 \%$ & 138 & $28.9 \%$ & 80 & $16.7 \%$ & 28 & $5.9 \%$ \\
\hline $55-64$ yrs & 428 & 285 & $66.6 \%$ & 157 & $36.7 \%$ & 101 & $23.6 \%$ & 49 & $11.4 \%$ \\
\hline $65-74$ yrs & 218 & 147 & $67.4 \%$ & 63 & $28.9 \%$ & 50 & $22.9 \%$ & 30 & $13.8 \%$ \\
\hline $75-84$ yrs & 121 & 81 & $66.9 \%$ & 30 & $24.8 \%$ & 11 & $9.1 \%$ & * & * \\
\hline $85+y r s$ & 56 & 39 & $69.6 \%$ & 14 & $25.0 \%$ & 6 & $10.7 \%$ & * & * \\
\hline \multicolumn{10}{|l|}{ Suicide Mechanism } \\
\hline Drugs/Overdose & 425 & 340 & $80.0 \%$ & 247 & $58.1 \%$ & 204 & $48.0 \%$ & 147 & $34.6 \%$ \\
\hline Solids or Liquids & 18 & 9 & $50.0 \%$ & 5 & $27.8 \%$ & * & * & * & * \\
\hline Gases and Vapors & 130 & 70 & $53.8 \%$ & 33 & $25.4 \%$ & 24 & $18.5 \%$ & 9 & $6.9 \%$ \\
\hline Hanging/Asphyxiation & 956 & 536 & $56.1 \%$ & 236 & $24.7 \%$ & 126 & $13.2 \%$ & 38 & $4.0 \%$ \\
\hline Firearm & 1743 & 998 & $57.3 \%$ & 465 & $26.7 \%$ & 294 & $16.9 \%$ & 118 & $6.8 \%$ \\
\hline Jumping & 59 & 38 & $64.4 \%$ & 22 & $37.3 \%$ & 13 & $22.0 \%$ & 7 & $11.9 \%$ \\
\hline Sharp Object & 45 & 22 & $48.9 \%$ & 16 & $35.6 \%$ & 10 & $22.2 \%$ & * & * \\
\hline Other/Unspecified & 89 & 57 & $64.0 \%$ & 34 & $38.2 \%$ & 24 & $27.0 \%$ & 8 & $9.0 \%$ \\
\hline \multicolumn{10}{|l|}{ Other Circumstances } \\
\hline No Known Mental Health Problem & 1489 & 723 & $48.6 \%$ & 271 & $18.2 \%$ & 170 & $11.4 \%$ & 94 & $6.3 \%$ \\
\hline Known Mental Health Problem & 1976 & 1347 & $68.2 \%$ & 787 & $39.8 \%$ & 529 & $26.8 \%$ & 237 & $12.0 \%$ \\
\hline No Known Physical Health Problem & 2171 & 1112 & $51.2 \%$ & 519 & $23.9 \%$ & 333 & $15.3 \%$ & 115 & $5.3 \%$ \\
\hline Known Physical Health Problem & 1294 & 958 & $74.0 \%$ & 539 & $41.7 \%$ & 366 & $28.3 \%$ & 216 & $16.7 \%$ \\
\hline No Known Alcohol or Substance Abuse Problem & 1979 & 1125 & $56.8 \%$ & 552 & $27.9 \%$ & 370 & $18.7 \%$ & 174 & $8.8 \%$ \\
\hline
\end{tabular}


Table 1 Colorado suicide deaths between 2015 and 2017, by PDMP linkage status, and benzodiazepine and opioid exposure status (Continued)

\begin{tabular}{|c|c|c|c|c|c|c|c|c|c|}
\hline & \multirow{2}{*}{$\begin{array}{l}\text { Total suicide deaths } \\
\text { Count }\end{array}$} & \multicolumn{2}{|c|}{$\begin{array}{l}\text { Linked to } \\
\text { PDMP record }\end{array}$} & \multicolumn{2}{|c|}{$\begin{array}{l}\text { Ever dispensed } \\
\text { benzodiazepine }\end{array}$} & \multicolumn{2}{|c|}{$\begin{array}{l}\text { Recent } \\
\text { benzodiazepine } \\
\text { exposure }^{\text {b }}\end{array}$} & \multicolumn{2}{|c|}{$\begin{array}{l}\text { Recent } \\
\text { benzodiazepine } \\
\text { and opioid } \\
\text { exposure }^{c}\end{array}$} \\
\hline & & Count & Percent & Count & Percent & Count & Percent & Count & Percent \\
\hline Known Alcohol or Substance Abuse Problem & 1486 & 945 & $63.6 \%$ & 506 & $34.1 \%$ & 329 & $22.1 \%$ & 157 & $10.6 \%$ \\
\hline \multicolumn{10}{|c|}{$\begin{array}{l}\text { All percents are based on total suicide deaths in category } \\
\text { * Indicates fewer than three suicide deaths in category } \\
\text { "Ever dispensed a benzodiazepine" is defined as having received a prescription for a benzodiazepine ever during the timeframe of the analysis (2014-2017) } \\
\text { b" Recent benzodiazepine exposure" is defined as benzodiazepines prescribed within } 30 \text { days of death or a positive toxicology for benzodiazepines post-mortem } \\
\text { c" Recent benzodiazepine and opioid exposure" is defined as those with recent benzodiazepine exposure who were also either prescribed an opioid within } 30 \\
\text { days of death, or had positive toxicology post-mortem for opioids }\end{array}$} \\
\hline
\end{tabular}

had a positive toxicology post-mortem for opioids. Recent benzodiazepine exposure was more common among females than males (34\% versus $16 \%$ ), with percentages increasing among older female adults (Table 1). Among suicide deaths, those who died via drug overdose were more likely to have had recent benzodiazepine exposure (48\%), compared to suicide deaths by firearm (17\%), hanging/asphyxiation (13\%) and all other methods (approximately 20\%).

We examined additional information about the person's circumstances and mental health issues at the time of death from the Colorado Violent Death Reporting System. Among all suicide deaths, 27\% with a known/ documented mental health issue had recent benzodiazepine exposure, while $11 \%$ had recent benzodiazepine exposure but no known or documented history of mental illness or treatment. Furthermore, 22\% of suicide deaths with a known substance abuse or alcohol abuse problem had recent benzodiazepine exposure. Those with a known/documented physical health problem were also more likely to have had recent benzodiazepine exposure (28\% versus $15 \%$ ) or both recent benzodiazepine and opioid exposure (17\% versus $5 \%$ ).

\section{Discussion}

We conducted a descriptive, public health assessment to determine whether benzodiazepine exposure was prevalent enough among Coloradans who died by suicide to warrant further investigation. This assessment indicated that almost a third of the persons who died by suicide during 2015-2017 had filled a benzodiazepine prescription during the 2014-2017 period or had positive toxicology post-mortem. Though persons had varying length of time between benzodiazepine prescription and the outcome of suicide death, $14 \%$ of the suicide deaths (almost half who ever filled a benzodiazepine prescription) had a prescription within 30 days of death. When recent benzodiazepine exposure included both benzodiazepine prescriptions within 30 days of death and/or postmortem toxicology results indicating benzodiazepines, recent benzodiazepine exposure increased to $20 \%$ of the suicide deaths. Recent exposure was higher than $20 \%$ for females $(34 \%)$ and persons who died via intentional drug overdose (48\%). Recent benzodiazepine exposure was twice as common among persons with a known mental health problem (27\%) than those without (11\%). In addition, recent benzodiazepine exposure was higher among persons with known physical problems (28\%) than those without (15\%). These findings suggest that benzodiazepine exposure among suicide deaths is prevalent enough to warrant further investigation.

A national suicide study of 27 states participating in the National Violent Death Reporting System (including Colorado) found that $21 \%$ of suicide deaths from poisoning in 2015 had benzodiazepine as the class of substance causing death [4]. This prevalence increased to $25 \%$ for the subgroup with a current diagnosis of a mental health condition documented in coroner/medical examiner or law enforcement reports [4]. Our public health assessment suggests that recent exposure (not cause of death) among suicide deaths by drug poisoning (48\%), which includes deaths with post-mortem toxicology results for benzodiazepine and a prescription within 30 days of death, was twice as prevalent as the $21 \%$ whose suicide death was caused by benzodiazepine in this national study.

The data in this assessment had many limitations. For example, we lacked information on reasons benzodiazepines were prescribed, whether prescriptions were taken as prescribed, or whether individuals abruptly stopped taking them or were tapering them on their own. We also lacked access to medical records, to assess the role of other medications or co-morbid conditions, including chronic pain. Due to small numbers, we did not assess if results varied for subpopulations defined by geography smaller than the state, such as for a county or city. In addition, we lacked access to an appropriate comparison group; hence, comparative risk could not be assessed. Given these limitations, our analysis was not meant to determine causality but to determine whether benzodiazepines and suicidality should be studied further from a population health perspective. 
Strengths of this public health assessment are its novel use of the existing PDMP and the Violent Death Reporting System (both available in almost all states) and its novel definition of recent benzodiazepine exposure. Other states can quickly replicate this public health assessment. Future research can focus on the specific groups with recent benzodiazepine exposure identified in this analysis: females, persons who died from an intentional drug overdose, persons with a known mental health problem, and persons with known physical health problems. To address the limitations of this public health assessment, further research should be undertaken to determine linkages between benzodiazepine use and suicidal ideation, with assessments of medical/mental health records to identify and account for potential confounding factors (such as pre-existing conditions that lead to suicidal ideation). State health agencies that have access to more in-depth medical and mental health data should consider conducting analyses to examine associations between suicide deaths or attempts and benzodiazepine dosage, length of use, and tapering, while controlling for confounders. Prescribing patterns, by specialty and provider type, should also be examined, to determine whether prescribing/tapering guidelines, continuing education, academic detailing, informed consent, limitations on amounts prescribed and dispensed for certain acute conditions, or other public health policies should be established for benzodiazepines. Qualitative studies of prescribers and patients receiving benzodiazepine prescriptions could explain needs and barriers related to benzodiazepine use and use of alternative treatment, when warranted.

Both state and federal governments have policy levers that can impact prescribing. The use and potential for abuse of benzodiazepines has drawn the attention of state policy makers in the past. In 1989, amid fears of addiction to this family of drugs, New York State moved to regulate benzodiazepine prescriptions and enacted strict rules around prescribing [23]. A few states followed suit. A second wave of policy attention occurred in the late 1990s and first decade of the twentyfirst century when family advocates became concerned about the over-prescription of these drugs for older adults and the sedating and amnesiac effects they could have. There was also concern that they increased the risks of falls, motor vehicle accidents, and other injuries. Policy makers responded by calling for informed consent procedures around prescribing and guidelines related to prescribing these medications for older adults [24]. Because of their deadly interaction with opioids, these drugs have again drawn attention from policy makers. To date, 15 states have enacted laws or promulgated regulations related to the co-prescribing of opioids and benzodiazepines. In addition, in 2016, the U.S. Food and
Drug Administration added warnings to drug labeling regarding co-prescribing of opioids and benzodiazepines [25]. The goal of these policies was to reduce risks of addiction, accidental overdose, or dangerous interactions between drug classes [26].

No state or federal agencies have directly addressed the risk of suicidality that may be associated with benzodiazepines themselves. The idea that withdrawal or abrupt tapering may elevate risk of suicide is not broadly discussed by policy makers or public health officials. Further study, as described previously, should clarify the issue, and if warranted, policy levers should be identified to help combat the nation's growing suicide crisis.

\section{Conclusion}

Benzodiazepines have been linked to suicidal ideation. Yet population level assessments of benzodiazepine exposure among suicide deaths are rare. Our epidemiologic assessment indicates a relatively high prevalence of recent benzodiazepine exposure that warrants further investigation from both clinical and public health perspectives, especially among women, people with a mental health issue, and/or people with a physical health problem.

\section{Abbreviations}

PDMP: Prescription Drug Monitoring Program; U.S.: United States

\section{Acknowledgements}

The authors would like to acknowledge the staff of the Colorado Prescription Drug Monitoring Program, Colorado Violent Death Reporting System, and Colorado's Office of the Registrar of Vital Statistics for their efforts in collecting and making available these critical data.

\section{Authors' contributions}

$T G, M B, K B, B G$, and $L M$ designed the study and directed its implementation. $M B$ and $K B$ analyzed the data. $T G, M B, K B, B G$, and $L M$ interpreted the data. $T G, K B, B G$, and $G K$ wrote the manuscript. AK reviewed and interpreted the toxicology articles. All authors read and approved the final manuscript.

\section{Funding}

This work was supported in part by the Centers for Disease Control and Prevention through the Prevention for States cooperative agreement 5 NU17CE002719-03-00 and the National Violent Death Reporting System cooperative agreement 5 NU17CE002593-05-00. The funding body played no role in the design of the study and collection, analysis, and interpretation of data and in writing the manuscript. The contents of this publication are solely the responsibility of the authors and do not necessarily represent the official views of the Colorado Department of Public Health and Environment or the Centers for Disease Control and Prevention in the United States Department of Health and Human Services.

\section{Availability of data and materials}

All databases used in this study, including the PDMP and the Colorado Violent Death Reporting System, and Colorado's Death Certificate Registry are authorized for public health use by Colorado law. Colorado state laws protect the confidentiality of the data utilized for this study; therefore, the authors cannot release identified data. For information on obtaining deidentified datasets, contact cdphe.healthstatistics@state.co.us or see https:// www.datarequest.dphe.state.co.us/requests/create.

The authors can respond to requests for summary information about the data linkage processes and analyses. 


\section{Ethics approval and consent to participate}

Colorado state law allows the Colorado Department of Public Health and Environment to collect detailed mortality data and conduct population-level analyses of the Colorado Prescription Drug Monitoring Program, Colorado's vital statistics (death certificate) data, and National Violent Death Reporting System data for public health purposes. Institutional Review Board approval was not obtained or needed, as this was not a research study but an epidemiologic investigation into a major public health issue affecting the state.

\section{Consent for publication}

Not applicable.

\section{Competing interests}

The authors declare that they have no competing interests.

Received: 11 February 2020 Accepted: 13 July 2020

Published online: 22 July 2020

\section{References}

1. Opioid Overdose Prevention Unit. Colorado Opioid Data Profile. Colorado Department of Public Health and Environment. 2018. https://www.colorado. gov/pacific/cdphe/prescription-drug-data-profiles. Accessed 24 Mar 2020.

2. Donoghue J, Lader M. Usage of benzodiazepines: A review. Int J Psychiatry Clin Pract. 2010;2:78-87. https://doi.org/10.3109/13651500903447810.

3. Olfson M, King M, Schoenbaum M. Benzodiazepine use in the United States. 136 JAMA Psychiatry. 2015:72(2):136-42.

4. Huerta C, Abbing-Karahagopian V, Requena G, et al. Exposure to benzodiazepines (anxiolytics, hypnotics and related drugs) in seven European electronic healthcare databases: a crossnational descriptive study from the PROTECT-EU project. Pharmacoepidemiol Drug Saf. 2016;25(Suppl. 1):56-65. https://doi.org/10.1002/pds.3825.

5. Blanco C, Han B, Jones CM, Johnson K, Compton WM. Prevalence and correlates of benzodiazepine use, misuse, and use disorders among adults in the United States. J Clin Psychiatry. 2018;79(6):18m12174. https://doi.org/ $10.4088 / J C P .18 \mathrm{~m} 12174$

6. Airagnes G, Lemogne C, Renuy A, et al. Prevalence of prescribed benzodiazepine long-term use in the French general population according to sociodemographic and clinical factors: findings from the CONSTANCES cohort. BMC Public Health. 2019;19:566. https://doi.org/10.1186/s12889-0196933-8.

7. Madruga CS, Paim TL, Palhares $\mathrm{HN}$, et al. Prevalence of and pathways to benzodiazepine use in Brazil: the role of depression, sleep, and sedentary lifestyle. Braz J Psychiatry. 2019;41(1):44-50. https://doi.org/10.1590/15164446-2018-0088.

8. Maust $D$, Lin LA, Blow FC. Benzodiazepine use and misuse among adults in the United States. Psychiatr Serv. 2019;70(2):97-106. https://doi.org/10.1176/ appi.ps.201800321.

9. Sake F, Wong K, Bartlett DJ, Saini B. Benzodiazepine usage and patient preference for alternative therapies: a descriptive study. Health Sci Rep. 2019:2:e116. https://doi.org/10.1002/hsr2.116.

10. Dodds TJ. Prescribed benzodiazepines and suicide risk: a review of the literature. Prim Care Companion CNS Disord. 2017;19(2):10.4088/PCC $16 r 02037$.

11. W M MC, Benca RM, Rosenquist PB, et al. Hypnotic medications and suicide: Risk, mechanisms, mitigation, and the FDA. Am J Psychiatry. 2017;174(1):1825.

12. Stone DM, Simon TR, Fowler KA, et al. Vital signs: Trends in state suicide rates - United States, 1999-2016 and circumstances contributing to suicide - 27 states, 2015. MMWR Morb Mortal Wkly Rep. 2018;67:620 https://stacks.cdc.gov/view/cdc/53785. Accessed 23 Mar 2020.

13. U.S. Office of the Surgeon General, National Action Alliance for Suicide Prevention. 2012 National strategy for suicide prevention: goals and objectives for action. Washington: HHS; 2012. https://theactionalliance.org/ resource/revised-national-strategy-suicide-prevention-2012. Accessed 23 Mar 2020.

14. World Health Organization. Suicide prevention: a global imperative. Geneva: WHO Press; 2014. https://www.who.int/mental_health/suicide-prevention/ world_report_2014/en/. Accessed 23 Mar 2020.

15. Reno E, Brown TL, Betz ME, et al. Suicide and high altitude: an integrative review. High Alt Med Biol. 2018;19(2):99-108. https://doi.org/10.1089/ham. 2016.0131 Epub 21 Nov 2017
16. Barbanoj MJ, Clos S, Romero S, Morte A, Giménez S, Lorenzo J, Luque A Dal-Ré R. Sleep laboratory study on single and repeated dose effects of paroxetine, alprazolam and their combination in healthy young volunteers. Neuropsychobiology. 2005:51(3):134-47. https://doi.org/10.1159/000085206.

17. Neale G, Smith AJ. Self-harm and suicide associated with benzodiazepine usage. Br J Gen Pract. 2007;57(538):407-8 PMID: 17504594.

18. Reeves RR, Karnal A. Complicated withdrawal phenomena during benzodiazepine cessation in older adults. J Am Osteopath Assoc. 2019; 119(5):327-31. https://doi.org/10.7556/jaoa.2019.055.

19. Brett J, Murnion B. Management of benzodiazepine misuse and dependence. Aust Prescr. 2015;38(5):152-5. https://doi.org/10.18773/ austprescr.2015.055.

20. Vinkers $\mathrm{CH}$, Olivier B. Mechanisms underlying tolerance after long-term benzodiazepine use: a future for subtype-selective GABAA receptor Mmodulators? Adv Pharmacol Sci. 2012;2012:416864. https://doi.org/10. 1155/2012/416864

21. Prescription Drug Monitoring Program, Colorado Department of Regulatory Agencies. Accessed August 2019 at https:/www.colorado.gov/dora-pdmp. Accessed 9 Aug 2019

22. Colorado Violent Death Reporting System, Colorado Department of Public Health and Environment. Accessed August 2019 at: https://www.colorado. gov/pacific/cdphe/colorado-violent-death-reporting-system. Accessed 9 Aug 2019

23. Weintraub M, Singh S, Byrne L, Maharaj K, Guttmacher L. Consequences of the 1989 New York state triplicate benzodiazepine prescription regulations. JAMA. 1991;266(17):2392-7.

24. Tilly J, Skowronski S, Ruiz S. "The Opioid Public Health Emergency and Older Adults." Administration for Community Living, 2017. https://acl.gov/ programs/addressing-opioid-crisis. Accessed 25 Mar 2020.

25. US. Food and Drug Adminisration. FDA warns about serious risks and death when combining opioid pain or cough medicines with benzodiazepines; requires its strongest warning. 2016. https://www.fda.gov/media/99761/ download. Accessed 25 Mar 2020.

26. Davis CS, Pierce M, Dasgupta N. Evolution and convergence of state laws governing controlled substance prescription monitoring programs, 19982011. Am J Public Health. 2014;104(8):1389-95. https://doi.org/10.2105/AJPH. 2014.301923.

\section{Publisher's Note}

Springer Nature remains neutral with regard to jurisdictional claims in published maps and institutional affiliations.

Ready to submit your research? Choose BMC and benefit from:

- fast, convenient online submission

- thorough peer review by experienced researchers in your field

- rapid publication on acceptance

- support for research data, including large and complex data types

- gold Open Access which fosters wider collaboration and increased citations

- maximum visibility for your research: over $100 \mathrm{M}$ website views per year

At BMC, research is always in progress.

Learn more biomedcentral.com/submission 